\title{
Enhancement of L-amino Acid Oxidase Production by Bacillus Subtilis H-8 With Oxygen-vector and Asymmetric Degradation of DL Arginine to D- arginine
}

\section{peng Xu}

Guangxi University of Science and Technology https://orcid.org/0000-0002-8592-2340

Changpei Pan

Guangxi University

Gongcheng Cui

Guangxi University

ChunYan Wei

Guangxi University

Lijuan Wang

Guangxi University

Yanting Li

Guangxi University

Xiangping Li ( $\square$ xiangpingli@163.com )

Guangxi University

Shihai Huang

Guangxi University

Original article

Keywords: Bacillus subtilis, phenyl isothiocyanate, centrifugation, decolorization

Posted Date: August 1st, 2020

DOI: https://doi.org/10.21203/rs.3.rs-46901/v1

License: (c) (i) This work is licensed under a Creative Commons Attribution 4.0 International License.

Read Full License

Version of Record: A version of this preprint was published at Biotechnology \& Biotechnological 
https://doi.org/10.1080/13102818.2020.1834454. 


\title{
Enhancement of L-amino acid oxidase production by Bacillus subtilis $\mathrm{H}-8$ with oxygen-vector and asymmetric degradation of DL arginine to D-arginine
}

\author{
Peng Xua ${ }^{\mathrm{a}, 1}$, Changpei Pan ${ }^{\mathrm{b}, 1}$,Gongcheng Cui ${ }^{\mathrm{a}}$,ChunYan Wei ${ }^{\mathrm{a}}$, Lijuan Wang ${ }^{\mathrm{a}}$,Yanting $\mathbf{L i}^{\mathrm{a}}$, \\ Xiangping $\mathrm{Li}^{\mathrm{c}}$, , Shihai Huanga,*
}

${ }^{a}$ College of Life Science and Technology, Guangxi University; ${ }^{b}$ Nanning science and technology enterprise incubation base Co., Ltd; ' College of Animal Science and Technology, Guangxi University

Abstract The Bacillus subtilis H-8 independently screened
by our laboratory can produce L-amino acid oxidase
(L-AAO), and DL-arginine can be degraded asymmetrically

by suspending the wet bacteria in the degradation liquid. By

adding oxygen-vectors to the fermentation medium, the collected amount of wet bacteria can be increased. Taking

n-dodecane, n-hexadecane, oleic acid, paraffin, and n-hexane

as oxygen-vectors, the optimal oxygen-vector oleic acid was

$1.2 \%(\mathrm{v} / \mathrm{v})$. The weight of wet cells increased by $66.83 \%$

compared with before, and the activity of L-AAO in fermentation broth increased by $38.88 \%$ compared with before. The standard sample DL-arginine was derivatized by phenyl isothiocyanate, and then subjected to high performance liquid chromatography(HPLC), and the obtained peak area and arginine content were used as standard curves to measure the DL-arginine. The content of D-arginine and L-arginine in the initial degradation solution was $50 \%$ each, and the bacterial cells are added to the initial degradation solution of DL-arginine. After 21 hours of reaction, L-arginine was completely Degraded, remaining $47 \%$ of D-arginine.D-alanine was easily extracted from the

*Corresponding author. Guangxi University.

E-mail address: 583803544@qq.com

${ }^{1}$ The first two authors contributed equally to these work 
reaction solution using cation-exchange resin,after

centrifugation, decolorization, concentration and vacuum

drying, and the chemical and optical purity of the extracted

d-alanine was 92.68 and $97.46 \%$, respectively.

\section{Key points}

1. Increase the amount of dissolved oxygen during fermentation of Bacillus subtilis by adding an oxygen-vector to obtain a large amount of wet cells and L-AAO.

2. De-asymmetric degradation of L-arginine in DL-arginine by L-AAO from Bacillus subtilis fermentation product, thereby obtaining D-arginine.

3. D-Arginine and L-Arginine are derived from phenyl isothiocyanate, and supelco chiral column $(25 \mathrm{~cm} \times 4.6 \mathrm{~mm}, 5$ $\mu \mathrm{m})$ is used to detect D-Arginine and L-Arginine in the degradation solution. The content of lysine.

\section{Introduction}

Each an essential amino acid has its optimal intake and minimum intake(Hoffer 2016).Because D-arginine is an unnatural amino acid, its content in nature is very small, so it needs to be obtained through industrial production. D-arginine plays an important role in improving the response of glucocorticoids to normal life pressure (Griselda 2011).

D-arginine plays an analgesic role during acute pain (Wolkart et al. 2004). D-arginine has protective effect on oxygen free radical induced cardiac injury (Suessenbacher et al. 2002; Martin et al. 2019). D-arginine can be used in many fields. In general, arginine can be classified into D-arginine and L-arginine according to its molecular structure of chiral (Moozeh et al. 2015) and optical rotation (Radkov et al. 2014).The existing production methods of D-arginine include microbial fermentation, bio chemical conversion, asymmetric resolution and asymmetric degradation.Asymmetric degradation is a method that directly utilizes the specificity and selectivity of enzymes in microbial cells to catalyze the oxidation of substrates. For example, L-AAO directly degrades L-amino acids in DL amino acids to produce the process of separation and purification of D-amino acids (Takahashi et al. 1997;Umemura et al. 1989). Microbial cells as a tool for the separation of 1-amino acids and D-amino acids in asymmetric degradation(Singh et al. 2009).Oxygen is a significant factor affecting the growth, metabolism and morphology of microorganisms. Increasing the amount of dissolved oxygen 
is conducive to the collection of Bacillus subtilis.Compounds

added to fermentation media that improve oxygen transfer to

microorganisms are defined as oxygen-vectors(Cascaval et al.

2006).oxygen-vector is a kind of organic solvent which has

no toxicity to microbial cells, can combine with oxygen in

the system, and is insoluble in water, and can transfer oxygen

to the fermentation system (Xu et al. 2014). oxygen-vector

addition technology is a new technology developed in 1980s.

It is found that oxygen-vector can carry oxygen from gas phase to liquid phase, providing more dissolved oxygen and higher oxygen solubility than water phase, especially in aerobic fermentation system(Zhu et al. 2014).It is important that oxygen-vector can solve the high cost problem of oxygen transfer in fermentation tank. Adding oxygen-vector is economical, simple and practical.

\section{Materials and methods}

\section{Materials}

Source of bacteria

Bacillus subtilis $\quad$ H-8 was isolated, screened and preserved

by College of life science and technology, Guangxi

University.
Reagents and Solutions

Reagent A: $1.2 \%$ (V / V) PITC acetonitrile solution.

Reagent B: 14\% (V / V) triethylamine (tea) acetonitrile solution.

Mobile phase A: $0.2 \mathrm{~mol} / \mathrm{L}$ acetic acid sodium acetate buffer solution with $\mathrm{pH} 6.5$.

Mobile phase B: acetonitrile: water: 4:1.

\section{Methods}

Selection of oxygen-vector and preparation of cell suspension

Bacillus subtilis $\quad$ H-8 was fermented for $24 \mathrm{~h}$ in a fermentor with $80 \%$ filling factor, at $30{ }^{\circ} \mathrm{C}$ with an aeration of $1.0 \mathrm{vvm}$ and agitation of $300 \mathrm{rpm}$. The oxygen-vector selected for fermentation and its added amount are 1.5\% n-dodecane, $1.5 \%$ n-hexadecane, $1.5 \%$ oleic acid, $1.5 \%$ paraffin, and $0.8 \% \mathrm{n}$-hexane.The fermentation medium was composed of (w/v) $2 \%$ dl-alanine, $0.5 \%$ yeast extract, $0.2 \% \quad \mathrm{~K}_{2} \mathrm{HPO}_{4}$, $0.09 \% \mathrm{MgSO}_{4} \cdot 7 \mathrm{H}_{2} \mathrm{O}$, and $0.02 \% \mathrm{CaCl}_{2}$. Determine the effect of different oxygen-vectors on the weight of wet bacteria and the enzyme activity of L-AAO, and select the best 
oxygen-vector. After fermentation, the cells are collected by

centrifugation ( $6500 \mathrm{~g}$ for $10 \mathrm{~min}$ ), washed twice with $0.9 \%$

saline and resuspended..

Determination of D-arginine and L-arginine in

\section{degradation solution}

Different optical isomers of arginine were derivatized with

phenyl isothiocyanate, and then the arginine isomers were

separated and determined by HPLC.

Derivatization of sample: add $1 \mathrm{ml}$ of diluted DL

arginine into $10 \mathrm{ml}$ centrifuge tube with pipette gun, add 1

$\mathrm{ml}$ reagent $\mathrm{A}$ and $1 \mathrm{ml}$ reagent $\mathrm{B}$ into $10 \mathrm{ml}$ centrifuge tube,

derivatize at room temperature without light shock for $1 \mathrm{~h}$,

then add $3 \mathrm{ml} \mathrm{n}$-hexane and extract for $2 \mathrm{~min}$ at room

temperature. The lower layer solution is used as the sample.

Detection conditions: Superco chiral column $(25 \mathrm{~cm} \times$

$4.6 \mathrm{~mm}, 5 \mu \mathrm{m}$ ); mobile phase A: mobile phase B: $5: 1$; total

flow rate of mobile phase A and mobile phase $\mathrm{B}: 1 \mathrm{ml} / \mathrm{min}$;

manual injection $20 \mu \mathrm{L}$; detection wavelength of UV

detector $254 \mathrm{~nm}$; column temperature of $25^{\circ} \mathrm{C}$.

Determination of the ability of bacteria to degrade DL
$4 \mathrm{~g}$ DL-arginine was added into $50 / 250 \mathrm{ml}$ initial degradation solution $\left(\mathrm{KH}_{2} \mathrm{PO}_{4} 5 \mathrm{~g} / \mathrm{L} 、 \mathrm{Mg}_{2} \mathrm{SO}_{4} \cdot 7 \mathrm{H}_{2} \mathrm{O} 2 \mathrm{~g} / \mathrm{L}\right.$ 、

$\mathrm{CaCl}_{2} 0.1 \mathrm{~g} / \mathrm{L} 、 \mathrm{pH}=7.0$ ) containing $3 \mathrm{~g}$ wet cells. The degradation temperature was $30{ }^{\circ} \mathrm{C}$, and the rotation speed of shaking table was $180 \mathrm{r} / \mathrm{min}$. The contents of D-arginine and L-arginine were determined every 3 hours, and each group was parallel three times. The ability of wet cells to degrade L-arginine in DL arginine was studied by HPLC.

\section{Extraction of d-alanine from the degradation mixture}

The isoelectric point of $\mathrm{D}$-arginine is 10.76 . The $\mathrm{pH}$ of the degradation solution containing amino acids is adjusted to 7, which is lower than the isoelectric point of $\mathrm{D}$-arginine. D-arginine is positively charged and can be combined with strong acid cation exchange resin. Finally, D-arginine is eluted with $2 \mathrm{~mol} / \mathrm{L}$ ammonia water, and the eluent is decolorized with $10 \mathrm{~g} / \mathrm{L}$ activated carbon. Then the activated carbon is centrifuged and filtered out. The decolorized eluent is at 55 The concentrated eluent was put into a $65{ }^{\circ} \mathrm{C}$ vacuum drying oven until D-arginine crystallized.

Determination of chemical purity and optical purity of

D-arginine 
The product D-arginine is dissolved in deionized water,

diluted to a suitable concentration, and the content of

D-arginine is measured by HPLC. The chemical purity of the

product D-arginine is determined as follows(Zhang et al.

$$
\mathrm{p}_{1}=\frac{\mathrm{wV}}{\mathrm{m}} \times 100 \%
$$

$\mathrm{P}_{1}$ : Chemical purity $(\%)$

w: D-arginine concentration $(\mathrm{mg} / \mathrm{L})$

v: Volume

m: Quality

Using deionized water as the reference solution, accurately

weigh $0.1 \mathrm{~g}$ product $\mathrm{D}$-arginine and $0.1 \mathrm{~g}$ pure product

D-arginine, respectively, and dissolve them in $100 \mathrm{~mL}$

deionized water. Use a polarimeter to determine the optical

rotation $\mathrm{a}$, product $\mathrm{D}$-The detection formula of arginine

optical purity is as follows:

$$
[\alpha]_{\lambda}^{T}=\frac{100 \mathrm{a}}{L C}
$$

$\alpha$ : Optical rotation

T: Determination temperature $\left({ }^{\circ} \mathrm{C}\right)$ $\lambda$ : Wavelength of light wave

L: Length of polarimeter (CM)

$\mathrm{C}$ : Mass of sample in $100 \mathrm{ml}$ solution $(\mathrm{g})$

The optical purity of the product is calculated according

to the optical rotation ratio of the measured sample. The

calculation formula is as follows:

$$
\mathrm{p}_{2}=\frac{A_{1}}{A_{2}} \times 100 \%
$$

$\mathrm{P}_{2}$ : Optical purity

$\mathrm{A}_{1}$ : Specific rotation of sample

$\mathrm{A}_{2}$ : Specific rotation of pure product

\section{Results}

\section{Selection of oxygen-vector}

Table 1 Effects of different oxygen-vectors on wet cell weight and enzyme

$$
\text { activity }
$$

24h wet L-AAO

$$
\text { Concentration } \% \quad \text { cell enzyme }
$$

oxygen-vector

$$
\text { (v/v) weight activity }
$$

(g) $\quad(\mathrm{U} / \mathrm{g})$ 


\begin{tabular}{cccc}
\hline Blank & 0 & 3.02 & 37.45 \\
N-hexadecane & 1.5 & 4.3 & 42.91 \\
N-dodecane & 1.5 & 3.8 & 40.67 \\
& & & \\
Oleic acid & 1.5 & 5.02 & 46.17 \\
& & & \\
Paraffin wax & 1.5 & 3.55 & 38.78 \\
& & & \\
N-hexane & 0.8 & 1.64 & 17.35 \\
\hline
\end{tabular}

\section{Determination of different isomers of arginine by HPLC}

It can be seen from Fig.1 that the retention time of

D-arginine on elution column is $9.09 \mathrm{~min}$, and that of

L-arginine is $5.12 \mathrm{~min}$. Therefore, it is an effective method to

detect D-arginine and L-arginine in DL arginine by derivatization with phenyl isothiocyanate.

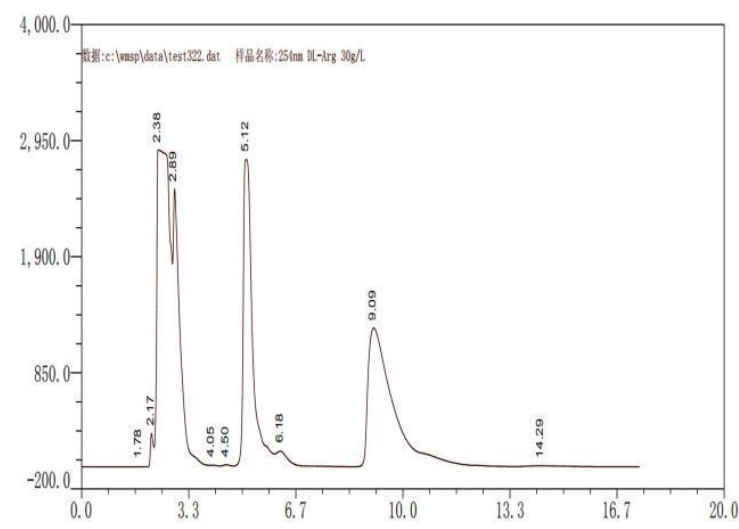

Fig.1 HPLC of different optical isomers of arginine.The standard sample DL column $(25 \mathrm{~cm} \times 4.6 \mathrm{~mm}, 5 \mu \mathrm{m})$; manual injection $20 \mu \mathrm{L}$, UV detection

wavelength $254 \mathrm{~nm}$; column temperature $25^{\circ} \mathrm{C}$; mobile phase A: mobile phase $\mathrm{B}$ :

$5: 1$; total flow rate: $1 \mathrm{ml} / \mathrm{min}$

\section{D-arginine and L-arginine standard curve}

It can be seen from Fig. 2 that the peak area in HPLC is linear with the content of D-arginine, and the regression equation is $\mathrm{y}=19226 \mathrm{x}-7632\left(\mathrm{R}^{2}=0.9998\right)$

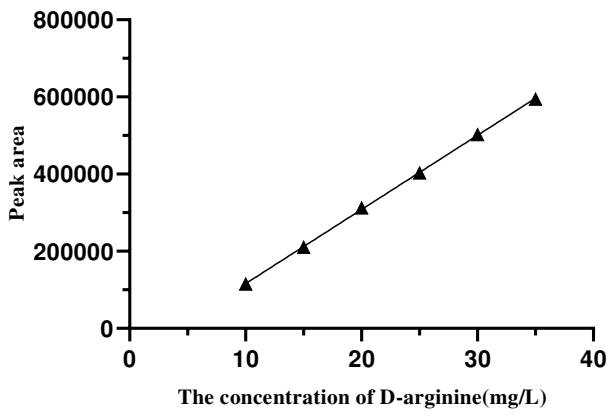

Fig. 2 Standard curve of D-arginine. Weigh a certain amount of $3.5 \%(w / v)$

D-arginine and dilute it with ultrapure water into a standard sample of a certain concentration. The sample was injected under the above chromatographic conditions to obtain a high performance liquid chromatogram.

It can be seen from Fig. 3 that the peak area in HPLC is linear with the content of L-arginine, and the regression equation is $\mathrm{y}=1937705 \mathrm{x}-799274\left(\mathrm{R}^{2}=0.9992\right)$. 


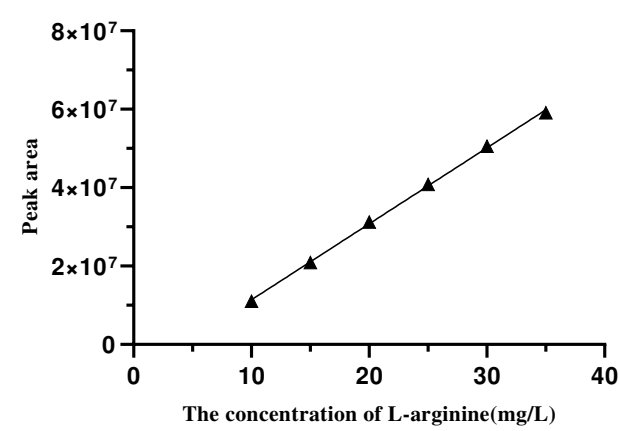

Fig. 3 Standard curve of L-arginine. Weigh a certain amount of $3.5 \%(w / v)$

L-arginine and dilute it with ultrapure water into a standard sample of a certain

concentration. The sample was injected under the above chromatographic

conditions to obtain a high performance liquid chromatogram.

Degradation of different isomers of arginine

It can be seen from Fig. 4 that the initial percentage content

of D-arginine and L-arginine is $50 \%$. After $21 \mathrm{~h}$ of reaction,

the percentage content of L-arginine is $0.7 \%$, while that of

$\mathrm{D}$-arginine is $47 \%$, and that of $\mathrm{D}$-arginine is $47 \%$

At $12 \mathrm{~h}$, the percentage of L-arginine decreased rapidly by

$37.4 \%$ and $11.9 \%$ from $12 \mathrm{~h}$ to $21 \mathrm{~h}$, indicating that the living

bacteria had the ability of asymmetric degradation of DL

arginine. Therefore, wet bacteria could consume L-arginine

in DL arginine and produce D-arginine under certain

conditions.

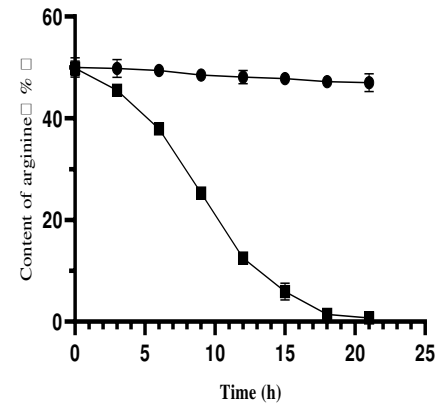

Content of

D-arginine (\%)

Content of

L-arginine( \%)
Fig.4 Dynamic changes of DL arginine degradation by Bacillus subtilis H-8.

The bacteria were added into the initial degradation solution containing DL

arginine

\section{Isolation of D-arginine and its purity}

D-arginine was isolated from the reaction mixture by using a simple procedure (see "Materials and methods" section). After cation exchange and drying, resulting in a yield of $91.58 \%$. The specific rotation of the obtained D-arginine was $[\alpha]_{\lambda}^{20}=-12.5^{\circ}$ at $20^{\circ} \mathrm{C}$. Besides, the chemical purity of the isolated and purified D-arginine was $92.68 \%$ and the optical purity was $97.46 \%$.

\section{Discussion}

Bacillus subtilis $\mathrm{H}-8$ possesses L-amino acid oxidase and not

D-amino acid oxidase and can carry out asymmetric

oxidative degradation of L-arginine from DL-arginine.

Besides, as this Bacillus subtilis $\mathrm{H}-8$ strain did not exhibit 
racemase activity and could not transform L-arginine into

D-arginine, and just consumes L-arginine, leaving D-arginine,

A similar paper has also been reported by Singh S (2009). In

order to obtain a large number of wet bacteria,

oxygen-vectors were added to the initial fermentation broth

to increase the dissolved oxygen in the fermentation broth

and solve the problem of low cell reproduction caused by

insufficient oxygen in the fermentation process(Wei et al.

2012). Blaga A C (2018) increased ergosterol production by

S. cerevisiae fed batch fermentation with n-dodecane as

oxygen-vector. The oxygen-vectors commonly used in

industrial production are n-hexadecane, n-dodecane, oleic

acid, paraffin and n-hexane. Oleic acid was selected as the

optimal oxygen-vector The weight increased by $66.83 \%$, and

the activity of L-amino acid oxidase increased by $38.88 \%$.

After cation exchange and drying, the chemical and optical

purity of the obtained D-arginine was $92.68 \%$ and $97.46 \%$.

In conclusion, L-arginine in DL arginine can be

degraded asymmetrically by Bacillus subtilis $\mathrm{H}-8$ to produce

D-arginine. Compared with other methods, Adding

oxygen-vector solves the high cost problem of oxygen

transfer in fermentation tank, which is economical, simple and practical.

\section{Abbreviations}

L-AAO,L-amino acid oxidase.

HLPC,High performance liquid chromatography.

\section{Availability of data and materials}

All data and materials are available from the corresponding

authors on reasonable request.

\section{Acknowledgements}

The authors are very grateful for the technical support provided by the College of Life Science and Technology,

Guangxi University.

\section{Funding}

Not applicable.

\section{Author information}

Peng $\mathrm{Xu}$ and Changpei Pan are contributed equally to this work.

\section{Affiliations}

College of Life Science and Technology, Guangxi

University. 
Peng Xu, Gongcheng Cui, Chunyan Wei, Lijuan Wang,

Yanting Li and Shihai Huang

College of Animal Science and Technology, Guangxi University.

Xiangping Li

Nanning science and technology enterprise incubation base

Co., Ltd

Changpei Pan

\section{Contributions}

Peng Xu and Changpei Pan conducted the experiments and analyzed the data. Gongcheng Cui and Chunyan Wei conceived and designed the study. Lijuan Wang and Yanting Li contributed to the experimental design and statistical analysis. Peng Xu and Changpei Pan wrote the first draft of the manuscript. Xiangping $\mathrm{Li}$ and Shihai Huang revised the manuscript completely. All authors read and approved the final manuscript.

\section{Corresponding authors}

Correspondence to Xiangping Li or Shihai Huang.
Ethics approval and consent to participate

Not applicable.

\section{Consent for publication}

Not applicable.

\section{Competing interests}

The authors declare that they have no competing interests

\section{Additional information}

\section{Publisher's Note}

Springer Nature remains neutral with regard to jurisdictional claims in published maps and institutional affiliations.

\section{References}

Hoffer L J(2016) Human Protein and Amino Acid Requirements. Journal of

Parenteral and Enteral Nutrition 40(4):460-474

https://doi.org/10.1177/0148607115624084

Griselda C M(2011)D-arginine action against neurotoxicity induced by

glucocorticoids in the brain. Neuroscience \& Biobehavioral Reviews 35(6)

1353-1362.https://doi.org/10.1016/j.neubiorev.2011.02.009

Wolkart G, Stessel H, Brunner F(2004) In vivo administration of d-arginine:

effects on blood pressure and vascular function in angiotensin II-induced

$\begin{array}{llll}\text { hypertensive } & \text { rats. } & \text { Atherosclerosis1 } & \text { 76:219-225 }\end{array}$

\section{Ethics declarations}


https://doi.org/10.1016/j.atherosclerosis.2004.05.016

Suessenbacher A, Lass A, Mayer B(2002)Antioxidative and myocardial

protective effects of L-arginine in oxygen radical-induced injury of isolated

perfused rat hearts. Naunyn-Schmiedeberg's Archives of Pharmacology

365(4):269-276.https://doi.org/10.1007/s00210-001-0523-9

Martin S, Desai K(2019)The effects of oral arginine on its metabolic

pathways in Sprague-Dawley rats. The British journal of nutrition

123(2).https://doi.org/10.1017/S0007114519002691

Moozeh K, So SM, Chin J(2015)Catalytic stereoinversion of L-Alanine to

$\begin{array}{lllll}\text { deuterated } & \text { D-Alanine. } & \text { Angew } & \text { Chem } & \text { 54:9381 }\end{array}$

https://doi.org/10.1002/anie.201503616

Radkov AD, Moe LA (2014) Bacterial synthesis of D-amino acids. Appl

Microbiol Biotechnol 98:5363.https://doi.org/10.1007/s00253-014-5726-3

Takahashi E, Furui M, Shibatani T.(1997)D-Amion acid production from

racemic amion acids by microbial asymmetric degrading Activity of Candida

maltisa.

Biotechnology

Techniques

11(12):913-916.https://doi.org/10.1023/A:1018470502118

Umemura I, Yanagiya K, Komatsubara S(1989)D-Alanine production by

Using Asymmetric Degrading Activity of Candida maltosa. Annals of the

New York Academy of Sciences

613(1):659-662.https://doi.org/10.1007/BF00172182

Singh S, Gogoi B K, Bezbaruah R L(2009)Optimization of mediun and cultivation conditions for L-amino acid oxidase production by Aspergillus

fumigatus. Canadian Journal of Microbiology

55(9):1096-1102.https://doi.org/10.1139/w09-068

Cascaval D, Galaction A L(2006)Folescu E. Comparative study on the effects of

n-dodecane addition on oxygen transfer in stirred bioreactors for simulated,

bacterial and yeasts broths. Biochemical Engineering Journal

33(1):56-66.https://doi.org/10.1016/j.bej.2006.05.019

Xu Z X, Bo F F, Xia J(2014)Effects of oxygen-vectors on the synthesis of epsilon-poly-lysine and the metabolic characterization of Streptomyces albulus PD-1. Biochemical Engineering Journal (94):58-64

https://doi.org/10.1016/j.bej.2014.11.009

Zhu P, Dong S, Li S(2014)Improvement of welan gum biosynthesis and transcriptional analysis of the genes responding to enhanced oxygen transfer by oxygen vectors in Sphingomonas sp. Biochem. Eng. J (90): 264271.https://doi.org/10.1016/j.bej.2014.06.011

Wei L Z, Abdul R R, Rosfarizan M(2012)Biosynthesis of high molecular weight hyaluronic acid by Streptococcus zooepidemicus using oxygen vector and optimum impeller tip speed. Journal of Bioscience and Bioengineering 114(3): 286-291.https://doi.org/10.1016/j.jbiosc.2012.04.011

Zhang Y Y, Li X P, Zhang C F(2017)Production of D-alanine from DL-alanine using immobilized cells of Bacillus subtilis HLZ-68. World Journal of 
Microbiology

Biotechnology

33(9):176-183.https://doi.org/10.1007/s11274-017-2341-3 


\section{Figures}

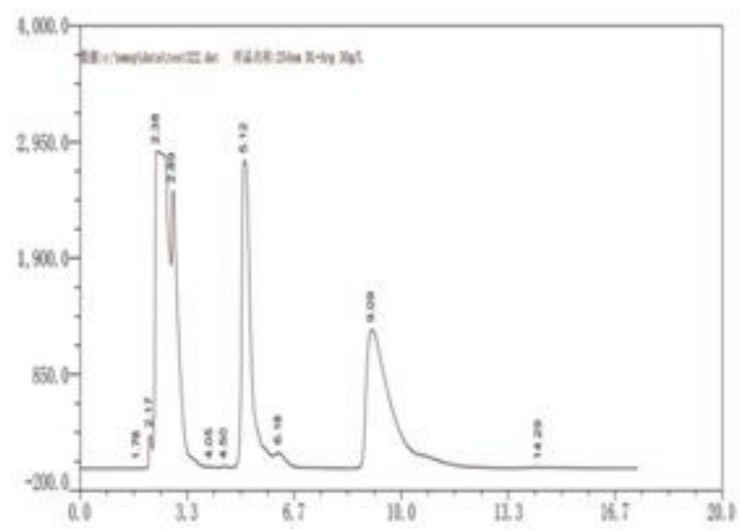

Figure 1

HPLC of different optical isomers of arginine. The standard sample DL arginine was pre -column derivatized, and the HPLC column was supelco chiral column $(25 \mathrm{~cm} \times 4.6 \mathrm{~mm}, 5 \mu \mathrm{m})$; manual injection $20 \mu \mathrm{L}$, UV detection wavelength $254 \mathrm{~nm}$; column temperature 25 ॠ; mobile phase A: mobile phase B: 5:1; total flow rate: $1 \mathrm{ml} / \mathrm{min}$.

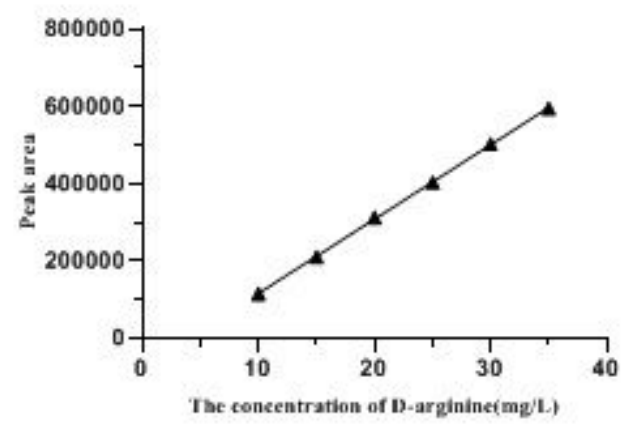

Figure 2

Standard curve of D-arginine. Weigh a certain amount of 3.5\% (w/v) D-arginine and dilute it with ultrapure water into a standard sample of a certain concentration. The sample was injected under the above chromatographic conditions to obtain a high performance liquid chromatogram.

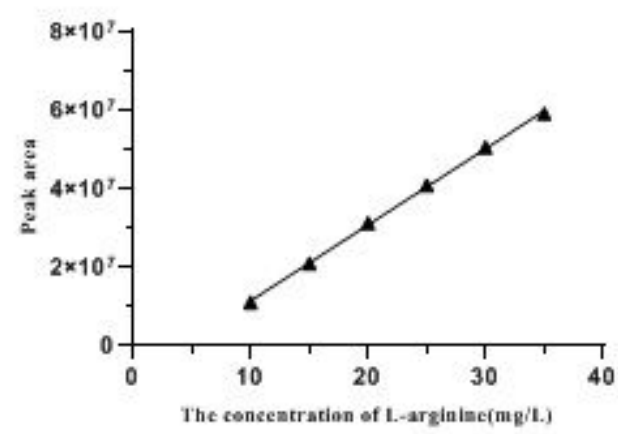

Figure 3 
Standard curve of L-arginine.Weigh a certain amount of 3.5\% (w/v) L-arginine and dilute it with ultrapure water into a standard sample of a certain concentration. The sample was injected under the above chromatographic conditions to obtain a high performance liquid chromatogram.

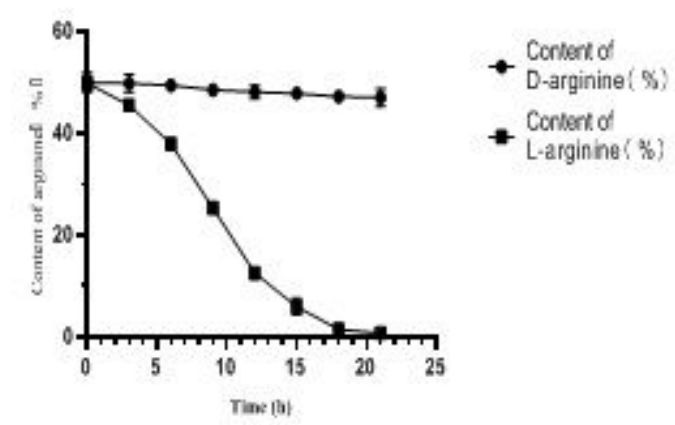

\section{Figure 4}

Dynamic changes of $\mathrm{DL}$ arginine degradation by Bacillus subtilis $\mathrm{H}-8$. The bacteria were added into the initial degradation solution containing $\mathrm{DL}$ arginine 